\title{
PENCIPTAAN BATIK POSTMODERN \\ (Pengadaptasian Elemen Artistik Lukisan Modern Indonesia dalam Teknik dan Motif Batik Tradisional Yogyakarta)
}

\author{
Aruman \\ Deni Junaedi \\ Isbandono Hariyanto *)
}

\begin{abstract}
Over time, traditional batik art continue to be explored and developed by a community of supporters. Various techniques and styles continue to emerge and inspire each other. Recognized the existence of the world community. Likewise with modern Indonesian painting, to date the work and the artist is able to leave a deep imprint for generations thereafter until today.

Starting from the traditional batik and painting modern Indonesia, known to this day through the creation of research - development possibilities of adapting the technique of batik and modern painting techniques, so as to give birth to a new style that can contribute to the survival of Yogyakarta batik. From the analysis of the traditional batik of Yogyakarta and painting modern Indonesia, found a wide variety of painting techniques and artistic elements that can be combined and used in batik techniques, in this case a blend of traditional and artistic batik art modern painting batik can be categorized as postmodernism, lifting the spirit of the old with a new style.
\end{abstract}

Keywords: motif, batik, postmodernism, painting, Yogyakarta

\section{INTISARI}

Seiring berjalannya waktu, seni batik tradisional terus digali dan dikembangkan oleh masyarakat pendukungnya. Berbagai teknik dan gaya terus bermunculan dan saling menginspirasi. Eksistensinya diakui masyarakat dunia. Begitu juga dengan seni lukis modern Indonesia, hingga saat ini karya dan senimannya mampu meninggalkan jejak yang mendalam bagi generasi setelahnya hingga saat ini.

Berawal dari batik tradisional dan lukisan modern Indonesia yang dikenal hingga saat ini melalui penelitian penciptaan - dikembangkan kemungkinan-kemungkinan pengadaptasian teknik batik dan teknik lukis modern, sehingga mampu melahirkan gaya baru yang dapat disumbangkan bagi kelangsungan batik di Yogyakarta. Dari hasil analisa batik tradisional Yogyakarta dan seni lukis modern Indonesia, didapati berbagai macam teknik lukis dan elemen artistik yang dapat dipadukan dan digunakan dalam teknik membatik, dalam hal ini perpaduan seni batik tradisional dan artistik seni lukis modern dapat dikategorikan sebagai batik postmodernisme, mengangkat spirit lama dengan gaya yang baru.

Kata kunci: motif, batik, postmodernisme, lukis, Yogyakarta

PENDAHULUAN

Pencapaian seni tradisional maupun seni modern Indonesia telah diakui masyarakat seni rupa baik dari dalam maupun luar negeri. Hal ini terindikasi pada batik, sebagai salah satu bentuk seni tradisional, yang pada tanggal 2 Oktober 2009 ditetapkan

*) Aruman, Isbandono (Aruman_ssn@yahoo.com), Staf Pengajar Program studi Kriya Seni, Jurusan Kriya, Fakultas Seni Rupa, Institut Seni Indonesia Yogyakarta.

Deni Junaedi (sejarahpanjang@yahoo.com), Staf Pengajar Program studi Kriya Seni, Jurusan Seni Rupa Murni, Fakultas Seni Rupa, Institut Seni Indonesia Yogyakarta. 
UNESCO sebagai warisan budaya dunia dari Indonesia (Prasetyo, 2010: 2). Demikian pula, penghargaan dari fora nasional maupun internasional disematkan untuk lukisan atau pelukis modern Indonsia, sebagaimana prestasi yang, antara lain, diperoleh Raden Saleh, Affandi, Fadjar Sidik, Nyoman Gunarsa, Heri Dono, maupun Putu Sutawijaya.

Batik, dalam kalkulasi J.L.A. Brandes, dinyatakan sebagai satu di antara sepuluh kekayaan budaya yang telah dimiliki bangsa Indonesia, khususnya Jawa, sebelum tersentuh budaya India (Haryono, 2008: 79).Sebaliknya, Denys Lombard (2008: 193) menulis bahwa teknik batik ada setelah Nusantara terpengaruh Indianisasi, tetapi sejarahnya tidak diketahui secara jelas. Rouffaer menyampaikan kemungkinan bahwa teknik batik berasal dari India atau Cina; namun paling tidak Lombard menekankan bahwa kemajuan teknik batik yang sesungguhnya terjadi di Pesisir Jawa pada abad ke-15 hingga ke-16. Akan tetapi, dari fakta artefak, jauh sebelum abad itu, motif kawung yang kini banyak diterapkan pada batik telah ada di patung Ganesatahun 1239, masa Kerajaan Singasari, yang ditemukan di Blitar (Kempers, 1959: 73).Terlepas dari perbedaan interpretasi sejarah tersebut, kini batik telah menjadi bagian yang tidak terpisahkan dari kehidupan masyarakat Indonesia. Budaya visual tersebut dimanfaatkan dalam berbagai peristiwa penting maupun aktivitas sehari-hari; dari gendongan bayi, pakaian mempelai, hiasan interior, hingga selimut jenazah.

Sementara itu, para pelukis Indonesia telah menerima berbagai penghargaan. Raden Saleh, sebagai pelukis Indonesia pertama yang menggunakan teknik dari Barat dan belajar langsung ke Belanda sejak tahun 1829, diberi penghargaan tertinggi dari Negeri Belanda. Seniman yang hidup di masa seni Romantisisme ini juga dianugerahi oleh Raja Saksen Coburg dan diangkat sebagai pelukis Istana Jerman (Kusnadi, 1991: 57).

Selain Saleh, Affandi juga tercatat sebagai pelukis dengan segudang prestasi. la mampu menciptakan teknik pribadi dengan cara menorehkan cat secara langsung dari tube ke kanvas. Pelukis yang pernah belajar di Shantiniketan India ini menerima gelar Doctor
Honoris Causadari University of Singapore tahun 1974. Dua tahun kemudian, seniman kelahiran Cirebon 1907 itu mendapat penghargaan Grand Maestro dari Komite Pusat Diplomatik Academy of Peace "Pax Mundi" di Castello Italia. Lalu pada tahun 1977, perupa yang kerap mendirikan perkumpulan seni tersebut meraih hadiah "Perdamaian Internasional" dari Yayasan Dag Hammarskyoult Florence, Italia (Burhan, 2012: 4). Karya dan piagam penghargaan pelukis otodidak yang pernah menjadi visiting professor di Ohio State University Amerika Serikat tahun 1962 itu dapat diamati di Museum Affandi Yogyakarta.

Jika seluruh penghargaan yang diterima perupa Indonesia dipaparkan tentu akan menyita beribu halaman. Dari genarasi ke genarasi selalu terukir prestasi: Nyoman Gunarsa, Abas Alibasyah, Entang Wiharso,Nyoman Masriadi, Putu Sutawijaya, dan seterusnya.

Kendati batik dan lukisan modern Indonesia telah menunjukkan prestasi gemilang, tetapi keduanya seringkali berjalan sendiri. Mereka dimasukkan dalam kotak yang berbeda, seni lukis ditaruh di kotak modern sedangkan batik disimpan di kotak tradisional. Dalam atmosfir akademis hal itu juga terasa, lukisan ada di wilayah seni murni sebagai representasi seni modern, batik ada di ranah seni kriya sebagai pengejawantahan seni tradisional. Padahal, penggabungan keduanya akan melahirkan karya yang menarik. Motif maupun teknik batik tradisional akan menjadi pesona tersendiri jika dipadukan dengan unsur artistik seni lukis modern Indonesia. Perpaduan seni tradisional dan modern seperti ini akan memasuki ranah estetika postmodernisme.

Postmodernisme, sebagaimana catatan Yasraf Amir Piliang (2003: 184), cenderung memperlakukan gaya sebagai suatu bentuk eklektikisme, yaitu kombinasi berbagai gaya dari berbagai seniman, periode, atau kebudayaan, dan meramunya menjadi satu gaya baru. George Ritzer (2004: 14-15) mendefinisikan, istilah "postmodernisme" merujuk pada produk kultural yang terlihat berbeda dari produk kultural modern; "postmodernitas" merupakan epos atau periode sosial dan politik yang biasanya 
terlihat mengiringi era modern dalam suatu pemahaman historis; "teori sosial postmodern" mengacu pada bentuk teori sosial yang berbeda dari teori sosial modern; jadi, "postmodern" meliputi epos historis baru, produk kultural baru, dan tipe teoretisasi baru mengenai dunia sosial.

Perpaduan antara batik tradisional dan lukisan modern akan lebih menantang jika apa yang diambil dari seni lukis modern adalah unsur artistik yang dibuat secara spontan, semacam goresan ekspresionistik dalam lukisan Affandi atau Putu Sutawijaya, karena garis spontan tersebut akan terpadu dengan motif batik yang cenderung terkontrol. Keberhasilan memadukan dua elemen artistik yang berbeda akan berbuah pada karya seni yang dinamis.

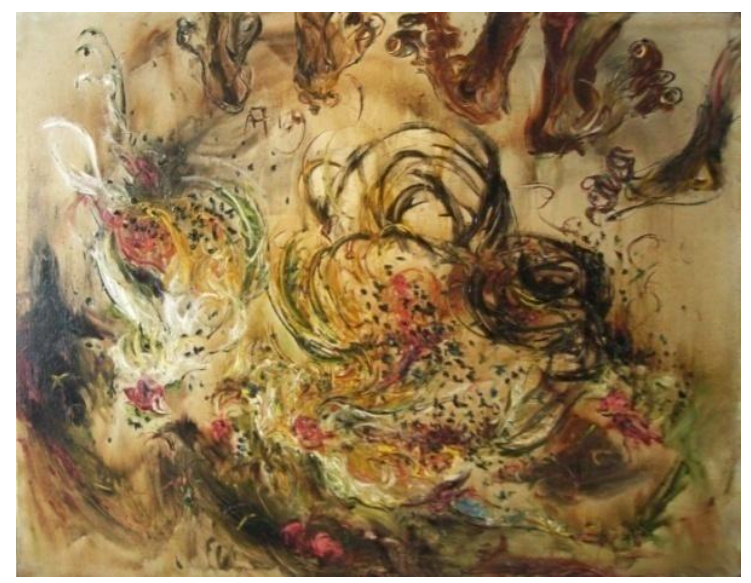

Gambar 1. Goresan spontan pada lukisan Affandi, Four Dead Roosters and The Foot, 1980, cat minyak di kanvas, $120 \times 144 \mathrm{~cm}$, di Museum Affandi Yogyakarta (Foto: Deni Junaedi, 2012)

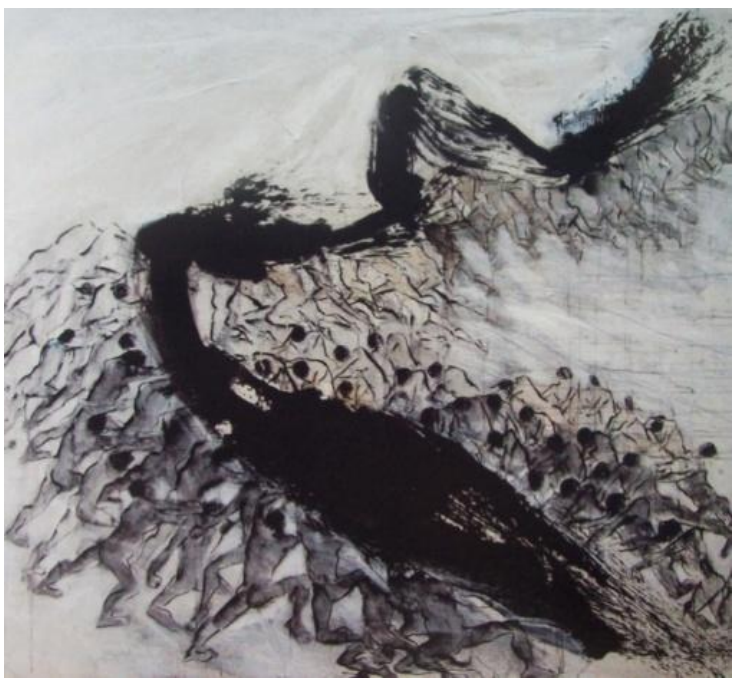

Gambar 2. Goresan spontan pada lukisan Putu Sutawijaya, Merapi, 2006, Media campuran di kanvas, 170 x $180 \mathrm{~cm}$ (Susanto dan Marianto, 2006, 81)
Untuk itu, penelitian tentang batik yang memanfaatkan elemen artistik seni lukis modern perlu dilakukan. Pada gilirannya, hasil penelitian ini dapat dinikmati masyarakat luas, dari tataran produsen hingga konsumen.

\section{Metode Penelitian}

Metode penelitian yang digunakan adalah metode penciptaan. Metode ini dibagi dalam dua tahap: tahap pertama adalah observasi data, dan tahap kedua adalah perancangan desain batik.

Data yang digali dalam penelitian ini dibedakan menjadi dua, yaitu data primer dan sekunder. Data primer diperoleh melalui penelitian lapangan, sedangkan data sekunder didapatkan dari dokumentasi dan berbagai sumber pustaka. Data primer dikumpulkan melalui dua metode, yaitu observasi dan wawancara. Data sekunder meliputi dokumentasi dan studi pustaka.

Pada tahap perancangan desain batik postmodernisme, tahapan yang ditempuh adalah menyeleksi motif batik dan lukisan, memadukan kedua obyek dalam bentuk sketsa, membuat komposisi warna, membuat desain dengan berbagai alternatif komposisi bentuk dan warna.

\section{PEMBAHASAN DAN HASIL}

\section{Bentuk dan Makna Motif Batik Tradisional Yogyakarta}

Berbicara tentang batik tradisional tidak bisa dilepaskan dari pembahasan tentang motif batik. Sebagaimana diungkapkan oleh M. Dwi Marianto (2002) bahwa untuk dapat mengkaji sebuah karya seni rupa khususnya batik, maka deskripsi yang harus dilakukan adalah dari aspek struktur atau susunan unsur-unsur motifnya secara menyeluruh. Hal ini menjadi penting mengingat motif batik merupakan kerangka gambaran atau unsur visual yang mewujudkan pola batik secara keseluruhan. Mendeskripsikan karya seni merupakan sebuah penggambaran secara verbal, sehingga ciri-ciri khusus dari suatu karya seni rupa dapat terlihat jelas, atau diketahui, dan pada akhirnya dapat diapresiasi.

Istilah batik tradisional sendiri sering dibandingkan dengan istilah batik modern. 
Batik modern adalah batik yang susunan motifnya tidak terikat oleh suatu aturan tertentu dan dengan isen-isen tertentu atau batik yang motif dan gayanya tidak seperti batik tradisional (BIPIK 20, 1994: 19). Batik modern bersifat bebas dan tidak mengikat.

Dengan demikian terdapat perbedaan antara batik tradisional dengan batik modern, di antaranya dari segi motif dan aturan yang berlaku. Dari segi motif, batik tradisional terikat oleh aturan tertentu sedangkan batik modern bersifat bebas dan abstrak. Dari segi aturan yang berlaku, batik tradisional harus mengikuti motif atau isen-isen atau motif yang sudah ada sebelumnya sedangkan batik modern tidak ada aturan yang membatasinya.

Dalam buku Batik Nusantara dijelaskan bahwa corak batik berdasarkan bentuk motifnya dibagi menjadi dua golongan, yaitu golongan ragam hias geometris dan nongeometris.

Corak hias geometris adalah corak hias yang mengandung unsur-unsur garis dan bangun seperti garis miring, bujur sangkar, persegi panjang, trapesium, belah ketupat, jajaran genjang, lingkaran dan bintang yang disusun secara berulang-ulang membentuk satu kesatuan corak. Corak yang termasuk ragam hias geometris antara lain:

\section{Corak Kawung}

Kawung merupakan sebuah pola yang telah berumur sangat tua. Motif ini terpahat pada relief candi-candi bersejarah (Prawirohardjo, 2011:15). Nama kawung berasal dari nama buah kawung, atau kolangkaling, yang berbentuk lonjong. Motif Kawung ini terbentuk oleh susunan lingkaran yang bersentuhan sehingga membentuk seperti buah aren yang dibelah (Samsi, 2007: 187).

Motif kawung diberi nama menurut ukuran bentuk bulat lonjong yang menyusun motifnya, yaitu: pertama, kawung bribil/kawung picis, apabila tersusun dari bentuk bulat lonjong kecil; kedua, kawung sen, jika tersusun dari bentuk bulat lonjong; ketiga; kawung benggol, apabila tersusun dari bentuk bulat lonjong besar (Soesanto, 1984: 54).

Pola kawung menurut Hardjonagoro Go Tik Swan, seorang empu batik klasik dari kota Sala, bermakna bahwa si pemakai pola diharapkan dapat berguna bagi orang banyak. Makna ini diandaikan pohon kawung, yang batang, daun, maupun buahnya berguna bagi manusia (Prawirohardjo, 2011: 15). Pada awalnya motif kawung ini dipakai raja dan keluarganya sebagai lambang keperkasaan dan keadilan (Riyantono dkk., 200: 32).

Pendapat lain mengatakan bahwa pola kawung menggambarkan perekonomian desa maupun azas gotong royong dan kerukunan. Pendapat ini dikaitkan dengan pembagian waktu masyarakat Jawa. Sejak berabad-abad yang lalu kelompok etnik Jawa menggunakan satuan waktu yang terdiri dari lima satuan hari, yaitu: Legi, Pahing, Pon, Wage, dan Kliwon; perhitungan ini disebut sepasar. Sepasar berasal dari kata pasar yang berarti tempat banyak orang berkumpul untuk melakukan kegiatan jual beli. Pola yang terdiri dari empat motif lonjong dengan sebuah pusat di tengah-tengahnya ini melambangkan lima desa yang saling berdekatan, yang masing-masing mendapat giliran sekali dalam lima hari untuk menjadi pasar pasar sebagai pusat penjualan hasil pertanian kelima desa tersebut. Makna dari gaya perekonomian semacam ini mengupayakan kerukunan dan kesejahteraan masyarakat di pedesaan (Prawirohardjo, 2011: 16).

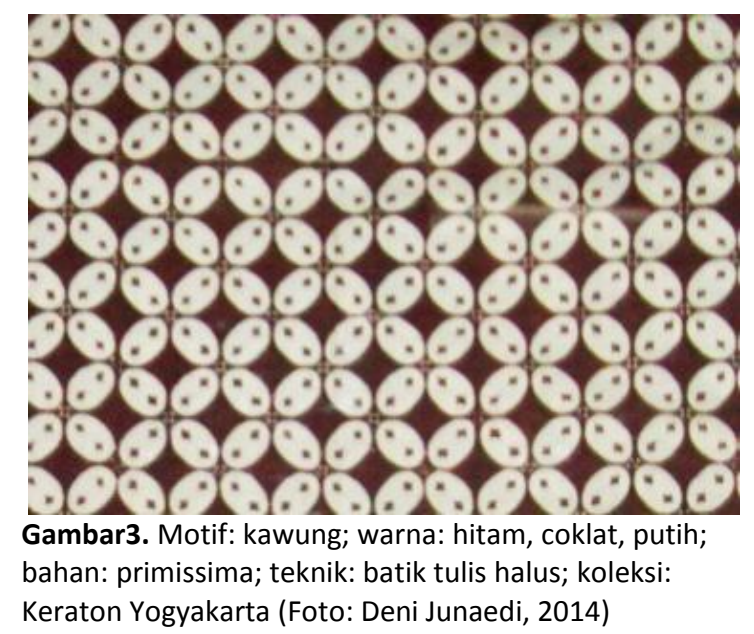

\section{Corak Parang dan Lereng}

Unsur-unsur bentuk parang rusak meliputi gubahan motif api atau disebut juga motif parang dan motif mlinjon yang berbentuk segi empat belah ketupat.

Masing-masing unsur yang terdapat dalam motif parang rusak memiliki makna 
simbolis. Antara lain, air dan api merupakan elemen hidup manusia.

Corak parang terdiri atas satu atau lebih ragam hias yang tersusun membentuk garis-garis sejajar dengan sudut kemiringan $45^{\circ}$. Contoh corak parang dan lereng adalah parang rusak (gambar 4).

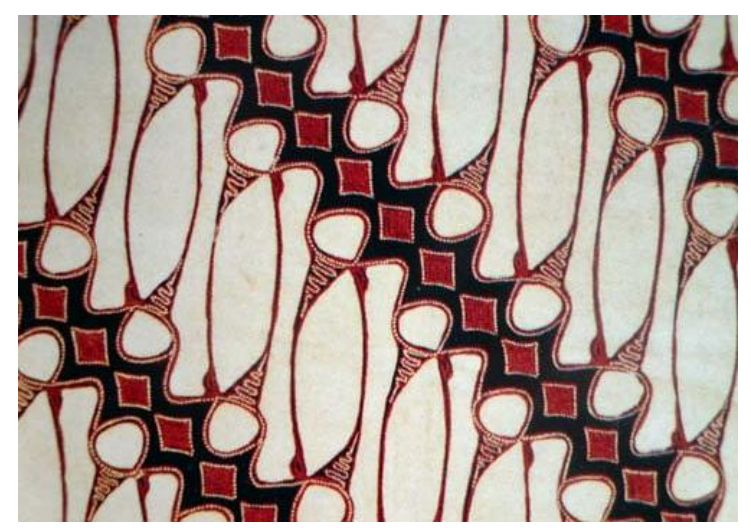

Gambar 4. Motif: parang rusak barong; warna: hitam soga hitam dan putih; bahan: primissima; teknik: batik cap (Sumber: batikencyclopedia.com/)

\section{Corak Truntum}

Motif truntum merupakan motif batik tradisional sebagai lambang cinta yang bersemi atau bertaut kembali. Konon motif ini tercipta tatkala permaisuri Susuhan Pakubuwono III sedang dilupakan oleh sang suami. Dalam kesedihan, sang istri selalu berdoa sambil membatik, maka terciptalah motif bintang-bintang. Akhirnya, ketekunan yang dilambari dengan keheningan mendekatkan diri kepada Sang Pencipta tersebut membuahkan hasil. Cinta sang raja kembali bersemi, dengan rasa kasih ia selalu menengok dan memperhatikan sang permasisuri yang tengah membatik (Riyantono, dkk, 2010: 30).

Motif truntum termasuk ke dalam motif ceplok, dan tergolong pola batik geometris. Motif truntum menggambarkan bunga dilihat dari depan, terletak pada bidang berbentuk segi empat. Truntum menurut $\mathrm{S}$. Prawiroatmodjo berarti tumbuh (Prawirohardjo, 2011: 18). Banyak orang yang mengartikan bahwa yang berarti tumbuh ialah cinta antara kedua pengantin; pada zaman dahulu kedua mempelai belum saling mengenal sebelum pernikahan.

Selain itu, ada pula yang berpendapat bahwa kata truntum berasal dari kata tumaruntum, yang berarti saling tuntun- menuntun. Dengan demikian, pola ini mengandung harapan agar kedua pengantin akan selalu tuntun-menuntun (Prawirohardjo, 2011: 19).

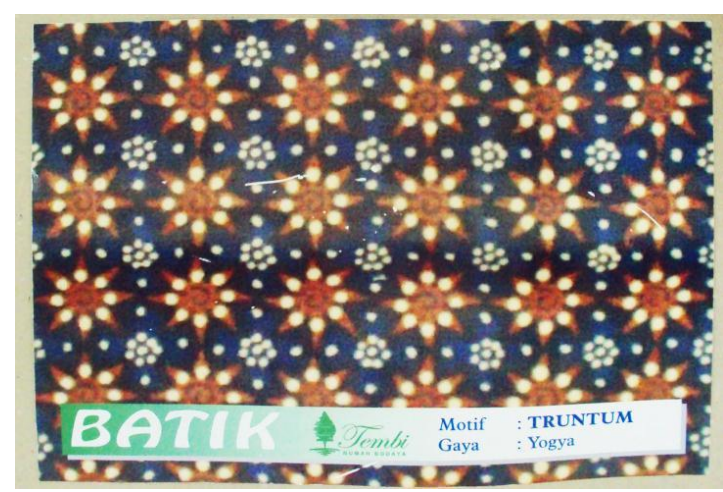

Gambar 5. Motif: truntum; warna: biru- coklat- putih; bahan: primissima; teknik: batik cap; koleksi: Tembi Rumah Budaya (Foto: Aruman, 2014)

\section{Corak Nongeometris}

Pola nongeometris merupakan pola dengan susunan tidak terukur, polanya tidak dapat diukur secara pasti. Corak dapat dibuat secara berulang. Pola yang termasuk ke dalam golongan pola ini, antara lain, adalah corak semen rama.

Motif batik semen rama termasuk ke dalam motif batik semen. Mari $S$. Condronegoro (1995: 20) menjelaskan bahwa motif batik semen ini dikenakan oleh para bangsawan yang menyandang gelar bupati nayaka, pengulu, garwa dalem, cucu, dan cicit sultan. Namun demikian, motif semen tanpa lukisan gunung (meru) dan sayap (lar) boleh dipakai oleh setiap orang.

Motif batik klasik dari jenis semen seperti pada motif semen rama, merupakan batik yang menggambarkan tumbuhan yang dikombinasikan dengan unsur-unsur motif lainnya yang tersusun secara harmoni tetapi tidak menurut bidang geometris. Pada bidang yang luas, terjadi pengulangan susunan motifmotifnya, sehingga menjadi pola yang menyeluruh dalam satu lembar kain (Susanto, 1980: 212-215).

Unsur visual batik semen rama terdiri dari delapan unsur pokok, yaitu: a) pohon hayat; 2) meru; 3) garuda; 4) binatang; 5) burung; 6) pusaka; 7) bangunan atau perahu; dan 8) lidah api. Pada unsur motif tambahan dapat dijumpai motif binatang, tumbuhan, bintang, dan motif dhampar (Widodo, 2007). 
Secara garis besar, penempatan unsur motif batik semen rama dibagi atau mengisi bidang persegi empat yang disebut dengan mandala. Mandala adalah lingkaran yang berada dalam persegi empat (terbatas) (Sumardjo, 2006: 185). Masing-masing dari bidang mandala tersebut terisi motif pokok maupun motif tambahan dengan berbagai variasi bentuk maupun ukurannya. Variasi dari penempatan motif juga ditemukan pada masing-masing bidang mandala tersebut sebagai pengulangan motif yang membentuk dan mewujudkan sebuah pola batik secara keseluruhan.

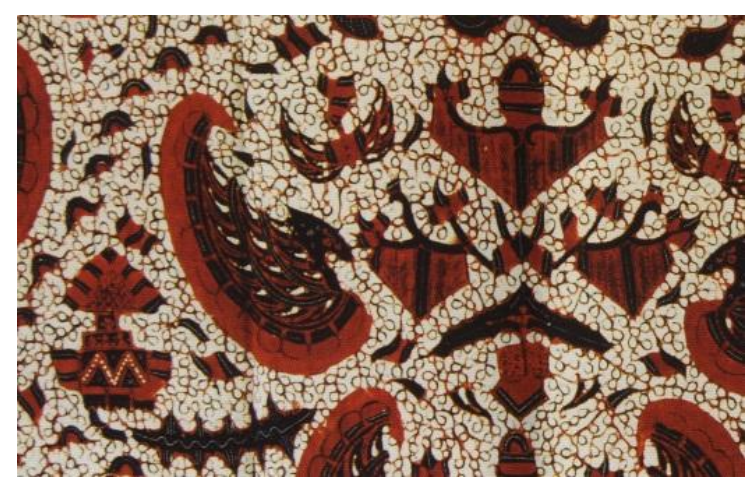

Gambar 6. Motif: semen rama: warna: hitam, coklat, putih: bahan: primissima (Foto: Isbandono, 2014)

Istilah semen rama terdiri atas dua kata. Kata "semen" berasal dari kata semi (bahasa Jawa) yang berarti tumbuh. Motif ini penuh dengan simbolisme yang menunjukkan pujaan terhadap kesuburan dan tata tertib alam semesta. Lambang ini bersangkutan dengan falsafah Jawa nunggak semi, yang berarti menciptakan yang baru dari yang lama atau yang tua. Dalam hal ini ada konotasi regenerasi atau pembaharuan (Femina, 1985: 9-10). Kata "rama" diduga merupakan nama tokoh utama dalam epik Ramayana (Soebadio dkk., 1997: 121). Pemakai batik motif semen rama diharapkan berbuat adil, berbudi luhur, tabah menghadapi segala cobaan hidup, dan mewarisi sifat-sifat Rama (Widodo, 2007:8687).

\section{Unsur, Teknik, Komposisi, dan Deformasi Lukisan Modern Indonesia}

Beberapa elemen artistik yang sering dipakai dalam seni lukis modern Indonesia tidak ditemukan dalam batik tradisional Yogyakarta. Maka jika terdapat upaya pemaduan elemen-elemen tersebut pada batik akan membuka peluang bentuk baru seni batik. Untuk itu, analisis terhadap elemen-elemen artistik seni lukis Indonesia yang tidak terdapat dalam batik perlu dilakukan. Selanjutnya, elemen tersebut akan dipadukan dengan batik tradisional Yogyakarta yang telah di bahas di muka.

Klasifikasi elemen artistik tersebut dapat dibagi menjadi tiga bagian, yaitu: teknik, unsur visual, komposisi, dan deformasi. Keempatnya mewujud menjadi bentuk (form) seni rupa. Bentuk menurut Marcia Muelder Eaton adalah hal yang ditampilkan secara langsung dan dipersepsi (Eaton, 2010: 102).

\section{Teknik}

Teknik, dalam pandangan Gene Mittler dan Rosalind Ragans, merupakan metode penciptaan karya seni (Ragans, 2005: 30-38). Dengan demikian teknik dalam seni lukis adalah metode yang digunakan pelukis dalam mengolah material sehingga menghasilkan suatu bentuk tertentu. Metode tersebut terrepresentasikan dalam bentuk visual pada lukisan.

Teknik dalam seni lukis yang tidak terdapat dalam batik tradisioal dan masih memungkinkan untuk diaplikasikan dalam batik adalah lelehan, cipatran, dan transparan. Teknik Lelehan

Teknik lelehan diciptakan dengan cara melelehkan cat yang encer di permukaan kanvas dari bagian atas ke bagian bawah. Sesuai dengan tabiat air yang mencari bagian rendah, dan juga tabiat air yang meresap ke pori-pori, pewarna yang tidak terlalu kental tadi akan terus meluncur ke bawah hingga habis. Bentuk yang spontan atau tanpa direncanakan sepenuhnya akan menambah nilai artistik. Bentuk seperti ini tidak muncul dalam batik tradisional yang rata-rata unsurnya terdiri dari bentuk yang terencana seutuhnya.

Contoh lelehan dapat dilihat dalam lukisan Our Last Tears karya I Putu Erry Karyawan. Di lukisan itu, pada bagian tengah ke bawah terdapat lelehan berwarna gelap pada bidang terang. 
Teknik Cipratan

Teknik cipratan dibuat dengan cara mencipratkan cat, yang biasanya juga tidak terlalu kental, secara langsung ke bidang lukiasan. Pada teknik ini tidak terdapat jejak sapuan kuas. Sebagaimana lelehan, teknik cipatran juga menghasilakan bentuk yang spontan. Seorang pelukis kadang menonjolkan hasil cipratan, tetapi kadang teknik tersebut sekedar dipakai untuk latar belakang.

Contoh cipratan dapat dilihat dalam lukisan I Made Sumadiyasa, Lava. Pada lukisan ini, cipatran warna putih dibuat menonjol, terutama yang berasal dari sisi kiri bawah menuju ke arah tengah. Akan tetapi, lukisan ini juga berisi cipratan-cipratan lain berwarna gelap di berbagai sisiyang lebih berfungsi sebagai latar belakang.
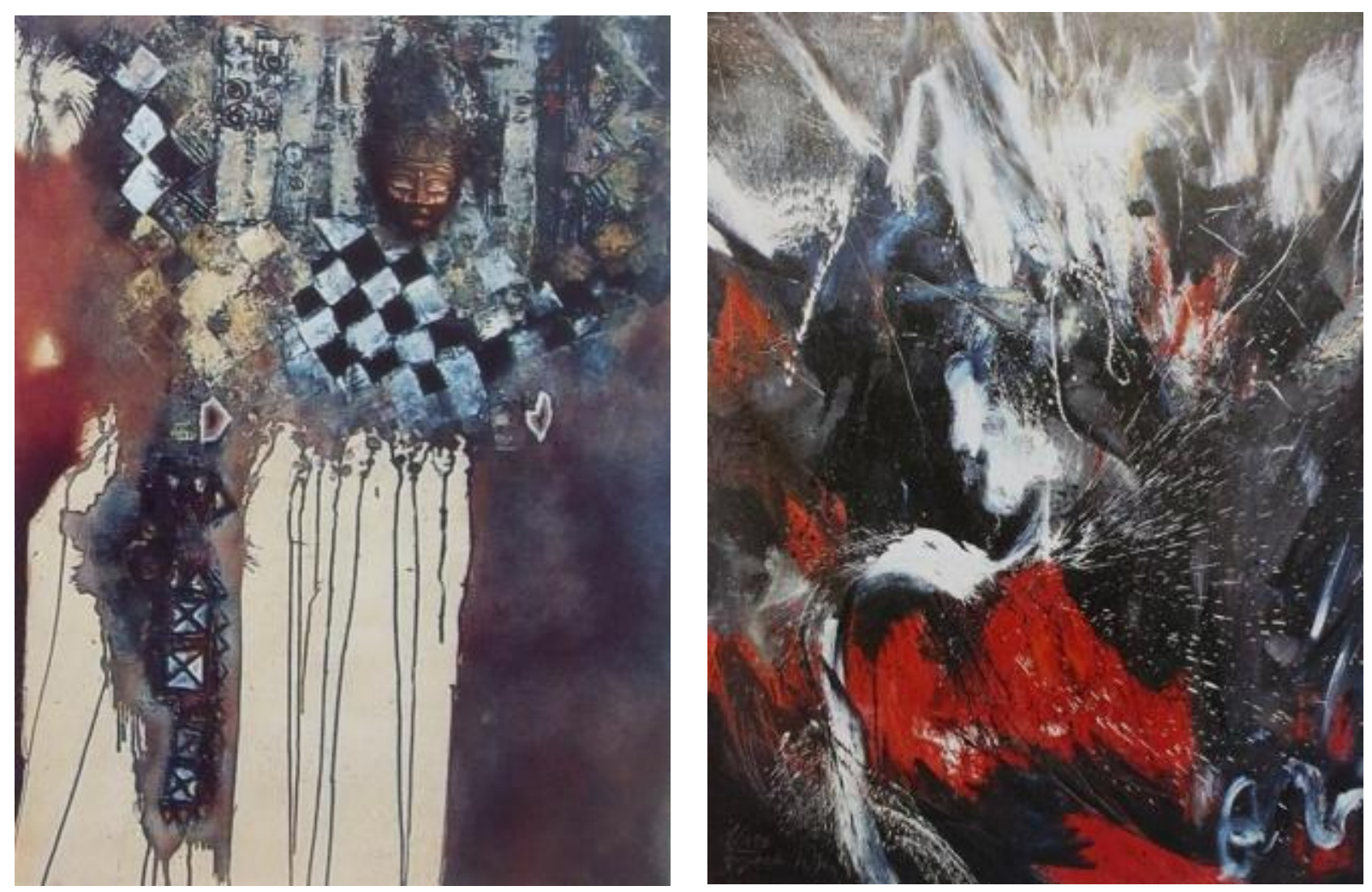

\section{Teknik Transparan \\ Teknik transparan adalah teknik} tembus pandan, dalam pengertian, warna atau bentuk yang ada di bawah masih terlihat meskipun di atasnya ditumpangi warna atau bentuk lain. Terkadang teknik ini disebut teknik aquarel, karena awalnya teknik ini digunakan dalam cat air.

Contoh teknik transparan tampak pada lukisan Affandi Self Potrait. Selain warna yang saling menumpang, pertemuan antara satu warna dengan warna yang lain, jika warna itu dikerjakan saat masih basah, akan saling menyatu. Dalam bahasa Jawa, efek seperti ini disebut mblobok.

Gambar 7. I Putu Erry Karyawan, 1999, Our Last Tears, $110 \times 145$ cm (Sumber: Katalog Philip Moris 1999, 40)

Gambar 8. I Made Sumadiyasa, Lava, 1996, $170 \times 145$ $\mathrm{cm}$, cat minyak di kanvas (Sumber: I Made Sumadiyasa, 99) 


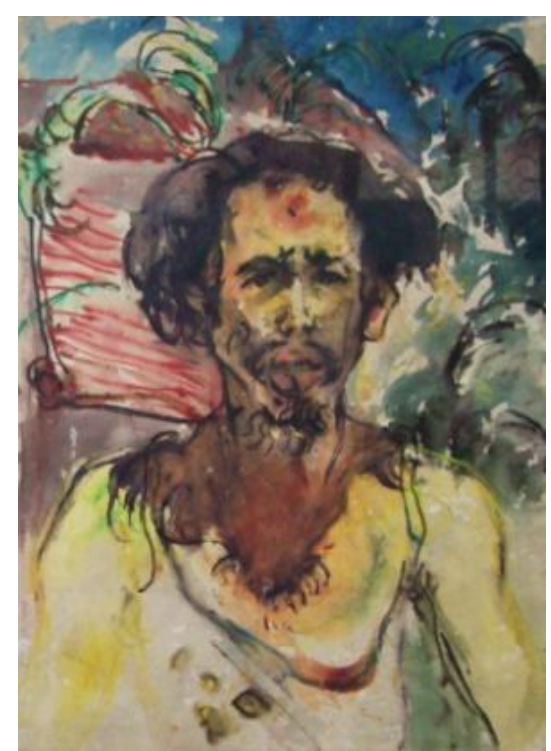

Gambar 9. Affandi, Self Potrait, 1944, 95×38cm, cat air di kertas (Foto: Deni Junaedi, 2012, di Museum Affandi)

\section{Unsur Visual}

Unsur visual adalah elemen-elemen dasar penyusun visual, seperti garis, warna, atau bidang (shape). Baik lukisan modern Indonesia maupun batik tradisional Yogyakarta terdiri dari garis, warna, maupun bidang. Akan tetapi, karakter unsur tersebut seringkali memiliki perbedaan.

Unsur visual yang ada dalam seni lukis Indonesia yang memungkinkan untuk diadaptasi dalam batik antara lain adalah garis spontan, tonalitas warna untuk pencahayaan, maupun tonalitas warna untuk keruangan.

\section{Garis Spontan}

Berbeda dengan seni batik, seni lukis kerap kali menggunakan garis spontan. Garis spontan adalah garis yang dibuat dengan spontanitas, umumnya digoreskan dengan cepat dan tanpa merasa takut keluar dari out line suatu bentuk. Namun demikian, karakter bentuknya tetap tertangkap. Sementara itu, batik cenderung menggunakan garis-garis yang terkontrol ketat seakan tidak diijinkan keluar dari pola yang telah ada. Karya Nyoman Gunarsa, Yellow Voice II, adalah contoh lukisan yang menerapkan garis spontan.

Tonalitas Warna untuk Pencahayaan

Perbedaan gerap terang warna, atau tonalitas warna, sering dimanfaat dalam seni lukis untuk menghadirkan citra cahaya. Benda yang tertimpa cahaya diberi warna terang, sementara bidang bayangan diwarnai gelap.
Pemakaian cahaya seperti ini sekaligus menghadirkan citra volume dan juga dapat menghadirkan dramatisasi suasana. Ini berbeda dengan batik tradisional yang menyebar gelap dan terang secara merata.

Contoh lukisan yang menerapkan tonalitas warna untuk pencahayaan adalah lukisan Lions and Snake Fightingkarya Raden Saleh. Kepala singa dibuat lebih terang jika dibanding dengan bentuk lain di sekelilingnya. Dengan demikian, kepala tersebut akan tampak lebih menonjol.

Tonalitas Warna untuk Keruangan

Selain dapat digunakan untuk menghadirkan kesan pencahayaan, tonalitas atau gelap terang warna dapat digunakan untuk menciptakan kesan keruangan atau perspektif warna. Bagian yang jauh umumnya menggunakan warna terang, sedangkan objek yang dekat dengan warna yang cenderung lebih gelap. Ini berbeda dengan batik, dan juga dengan seni lukis dekoratif pada umumnya, yang memang tidak bermaksud menghadirkan keruangan.

Karya pelukis Mooi Indie, Abdullah Suriosubroto, yang berjudul Merapi menunjukkan penciptaan keruangan berbasis tonalitas warna. Warna gunung maupun hamparan tanah dan sawah yang ada di kejauhan dibuat jauh lebih terang dibandingkan dengan pohon maupun sawah yang ada di muka.

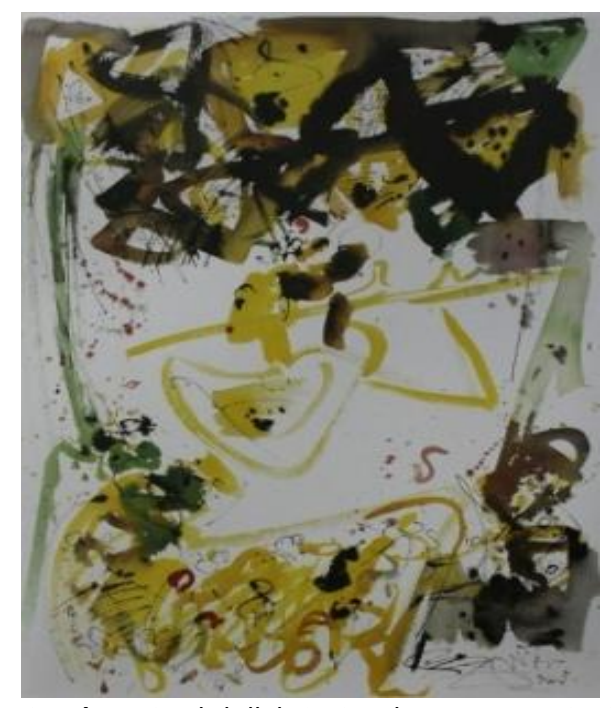

Gambar 12. Abdullah Suriosubroto, Merapi, 1930an, cat minyak di kanvas, 45 x $95 \mathrm{~cm}$ (Foto: Koleksi Mikke Susanto) 


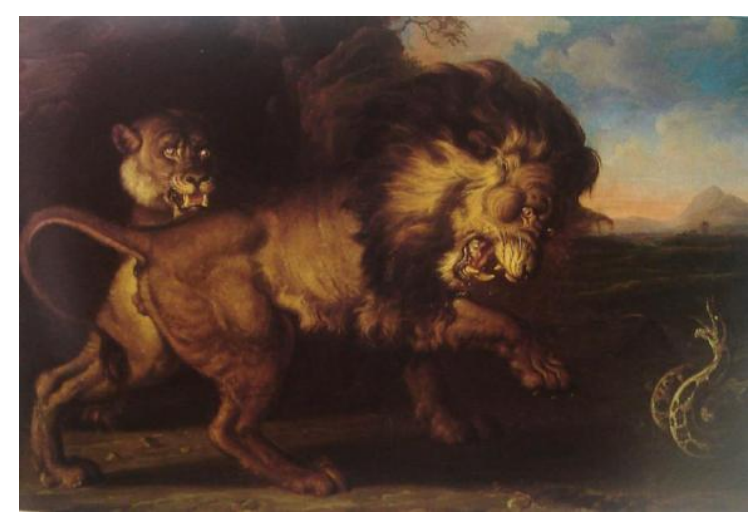

Gambar 10. Nyoman Gunarsa, Yellow Voice II, 2000, 76 x $56 \mathrm{~cm}$, cat air di kertas (Sumber: Spanjaard, 247)

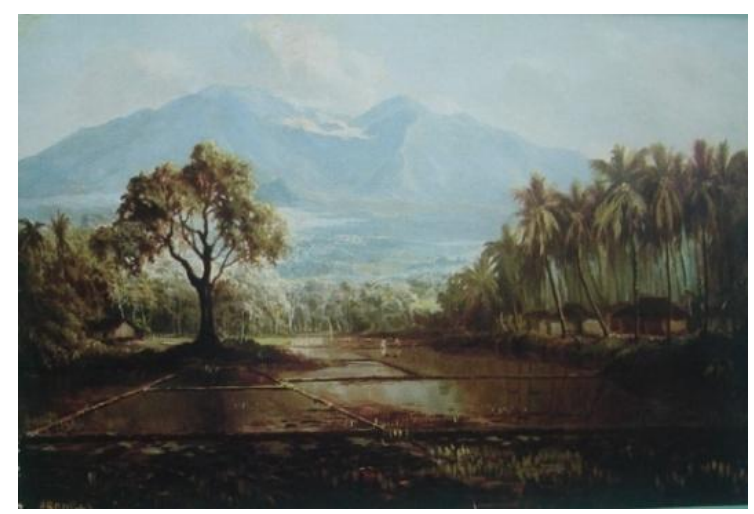

Gambar 11. Raden Saleh, Lions and Snake Fighting, 1839, cat minyak di kanvas, 122 x 175,5 cm (Foto: Koleksi Mikke Susanto)

\section{Komposisi}

\section{Komposisi Asimetris}

Komposisi asimetri adalah komposisi elemen-elemen visual yang antara bidang satu dengan bidang lain tidak memiliki kesamaan. Misalnya adalah bidang kanan berbeda dengan bidang kiri, atau bidang bawah berlainan dari bidang atas. Namun demikian, komposisi asimetris tidak menimbulkan ketimpangan tatapi justru membangkitkan kesan dinamis. Komposisi asimetri jarang ditemui pada batik tradisional. Pada umumnya, seluruh elemen batik tradisional dikomposisikan secara merata dan seimbang pada tiap bagian.

Contoh komposisi asimetri adalah lukisan New Natureciptaan Made Djirna. Dalam lukisan ini komposisi bidang kanan berbeda dengan bidang kiri. Bidang kanan dipenuhi dengan warna gelap sedangkan bidang kiri, yang hanya menempati sepertiga bagian, diisi dengan warna terang. Bentuk setengah lingkaran ditempatkan pada pertemuan dua warna tersebut sebagai penyatu keduanya.

\section{Komposisi Citra Keruangan}

Selain dengan tonalitas warna, keruangan juga dapat dicitrakan dengan pengkomposisian unsur bidang. Bidang yang besar biasanya akan dipersepsi menempati bagian depan, sebaliknya bidang yang kecil akan dipersepsi menempati bagian belakang. Umumnya, bagaian yang akan ditampilkan di bagian belakang dikomposisikan di sebelah atas, sementara itu bagian depan menempati komposisi sebelah bawah. Komposisi semacam ini tidak ditemukan dalam batik tradisional yang biasanya akan mencitrakan komposisi tiap bidang secara datar.

Contoh komposisi keruangan dapat dilihat pada lukisan Djoko Pekik, Shard-Eating Street Performers. Pada karya ini, objek yang ada di depan, yaitu para penari, dibuat lebih besar dan ada di bagian bawah bidang kanvas. Adapun para penonton dibuat lebih kecil dan dikomposisikan di sisi atas.

\section{Komposisi Ruang Kosong \\ Komposisi ruang kosong adalah} membiarkan suatu bidang tanpa diisi objek apapun, atau objek pengisinya tidak menonjol, sementara bidang lain diisi dengan suatu bentuk tertentu. Ruang kosong penting untuk dinamika komposisi. Ruang kosong di satu sisi ibarat tempat bernafas bagi bentuk yang dikomposisikan secara penuh di sisi lain. Batik tradisional biasanya tidak menggunakan ruang kosong. Unsur visual pada batik tadisional umumnya ditempatkan secara merata pada berbagai sisi.

17 Asma Tuhan, karya AD. Pirous, memanfaatkan ruang kosong. la membiarkan bagian tengah karyanya tidak terisi apapun kecuali warna gelap. Sementara itu di bagian atas maupun bawah diisi dengan kaligrafi Arab. 


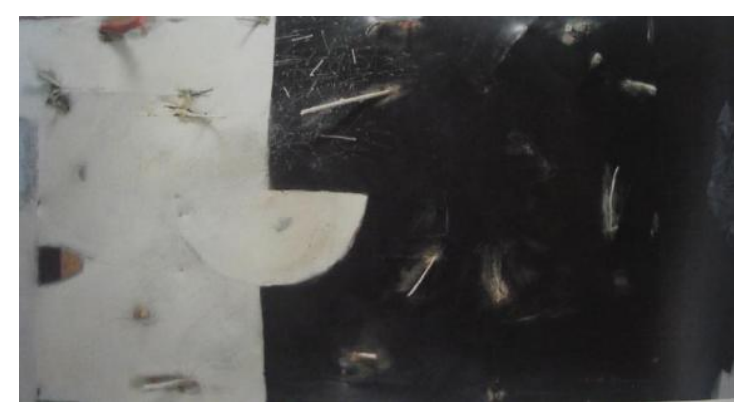

Gambar 13. Made Djirna, New Nature, 1994, Media campuran, 151,5 x 254,5 cm (Foto: Koleksi Mikke Susanto)

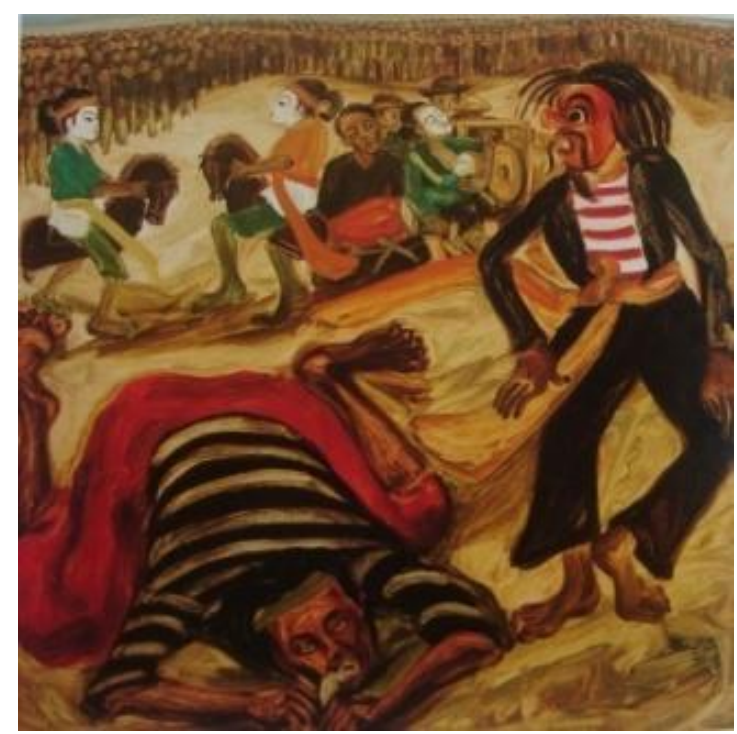

Gambar 14. Djoko Pekik, Shard-Eating Street Performers, 1989, cat minya di kanvas, 147 x $147 \mathrm{~cm}$

(Foto: Koleksi Mikke Susanto)

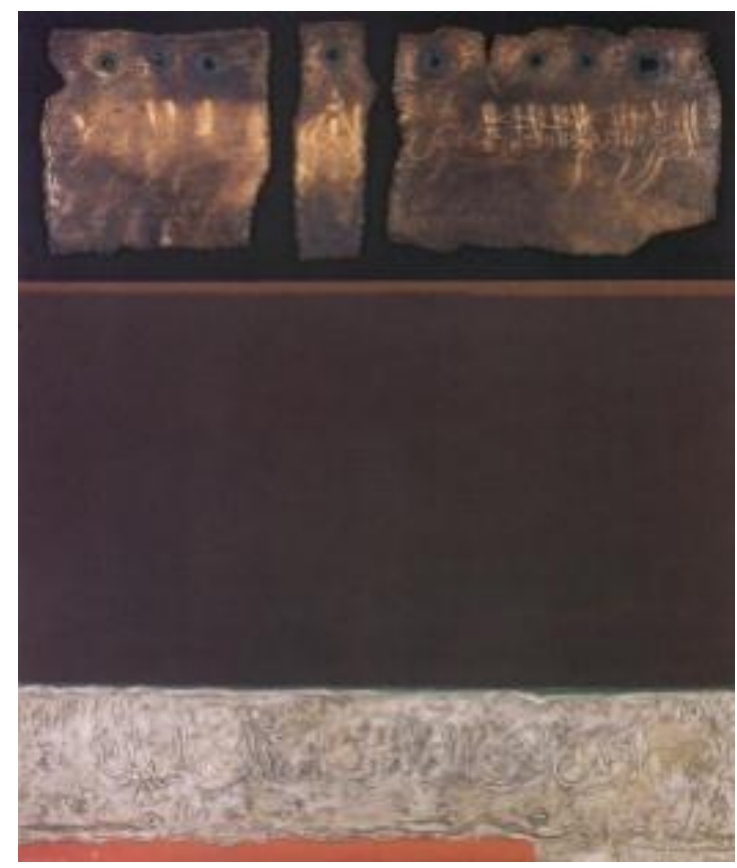

Gambar 15. AD Pirous, 17 Asma Tuhan, 1980, $140 \times 120$ $\mathrm{cm}$, media campuran (Foto: Koleksi Mikke Susanto)

\section{Deformasi}

Secara harfiah, deformasi (deformation) berarti 'perubahan bentuk'; istilah ini tersusun dari kata de yang berarti 'perubahan' atau 'pembokaran' dan form yang berarti 'bentuk'. Secara teknis, lukisan deformasi berarti lukisan yang citra kebentukannya telah diubah tidak seperti bentuk yang ada pada keadaan natural.

Paling tidak, lukisan deformasi dapat dibagi menjadi empat jenis, yaitu: distorsi, stilisasi, simplifikasi, dan destruksi. Stilisasi adalah penghiasan bentuk secara ornamentik. Distorsi adalah perubahan bentuk dengan cara pemiuhan. Simplifikasi adalah penyederhanaan bentuk.Destruksi adalah perusakan struktur bentuk.Dalam batik, umumnya hanya menerapkan deformasi stilisasi, untuk itu eksplorasi ke jenis deformasi lainnya membuka peluang desain baru untuk batik.

\section{Deformasi Distorsi}

Lukisan deformasi distorsi adalah lukisan yang bentuknya dirubah dengan cara pemiuhan. Proporsi antara satu bagian dengan bagian lainnya menjadi tidak realistis, misalnya kepala tampak lebih kecil dibandingkan dengan tangan. Dengan demikian, ciri utama deformasi jenis ini adalah perubahan proporsi dari proporsi realistis.

Contoh lukisan deformasi adalah lukisan Lelaki dengan Pedang Pendek karya I Nyoman Masriadi. Lengan kiri lelaki itu dibuat lebih pendek dari lengan yang sesungguhnya atau dari lengan kanannya. Telapak kaki tampak sangat kecil.

\section{Deformasi Simplifikasi}

Bentuk pada lukisan deformasi simplifikasi dibuat sesederhana mungkin namun tetap tidak kehilangan karakternya; dengan demikian karakter bentuknya masih dapat dikenali, atau bahkan ditonjolkan.Berbeda dengan stilisasi yang berlimpah ornamen, simplifikasi berusaha meredam atau jika perlu menghilangkannya. Umumnya bentuk dalam lukisan seperti ini ditangkap dari sudut pandang yang paling spesifik, misalnya, kapal akan digambar dari samping, bukan dari depan. 
Lukisan Rusli yang berjudul Buahbuahan termasuk deformasi simplifikasi yang tergolong ekstrim. Buah jeruk, apel, atau sejenisnya dibuat dengan cara sederhana, yaitu lingkaran. Karakter pangkal tangkai yang menjadi ciri khas buah tidak ditinggalkan.

\section{Deformasi Destruksi}

Deformasi destruksi adalah lukisan yang kebentukannya telah mengalami pengubahan atau perusakan struktur. Struktur suatu objek tidak lagi terlihat seperti apa adanya. Struktur figur binatang, misalnya, kaki tidak selalu terletak di bagian dekat perut, tetapi dapat dikaitkan di kepala atau di luar tubuh.Bahkan, organ binatang tersebut dapat diganti dengan mesin.

Eddie Hara mampu menjalajahi kebebasan destruksi lewat lukisan Lost in Wasteland. la tidak canggung untuk membuat kepala bermulut tiga yang salah satu lidahnya menjadi kaki figur lainnya. Bahkan, ia tidak peduli lagi dengan hukum grafitasi, organorgan aneh ditebarkan jungkir-balik di berbagai bidang.

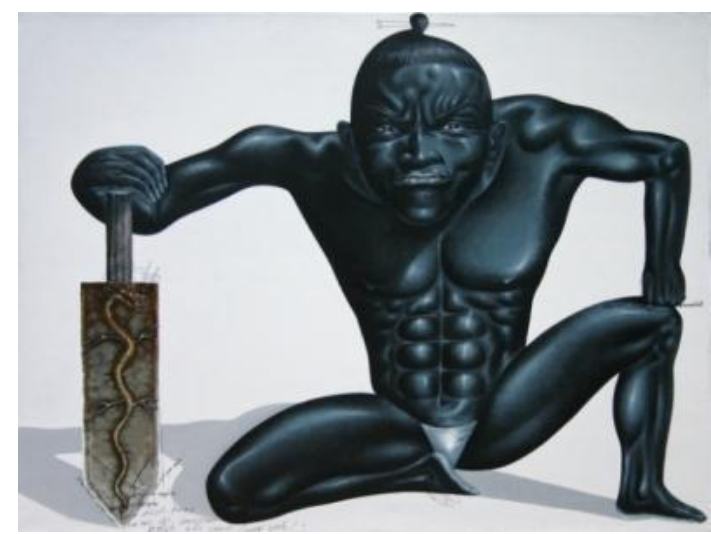

Gambar 16. I Nyoman Masriadi Lelaki dengan Pedang Pendek, 2006, akrilik di kanvas, $140 \times 105$ cm (Foto: Koleksi Mikke Susanto)

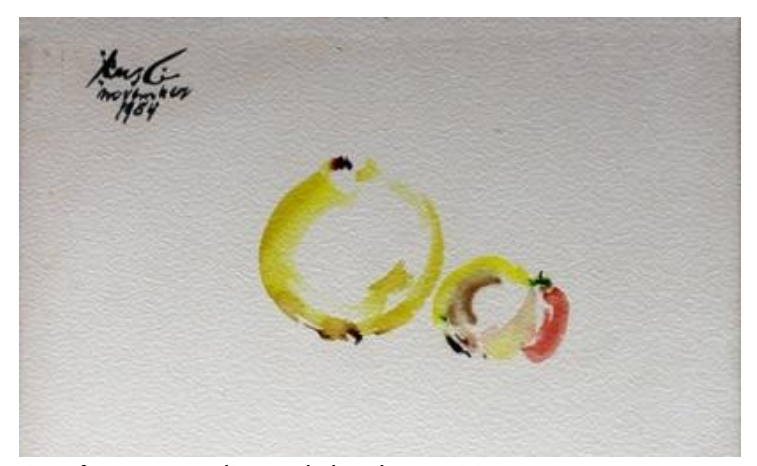

Gambar 17. Rusli, Buah-buahan, 1984, cat air di kertas (Foto: Deni Junaedi)

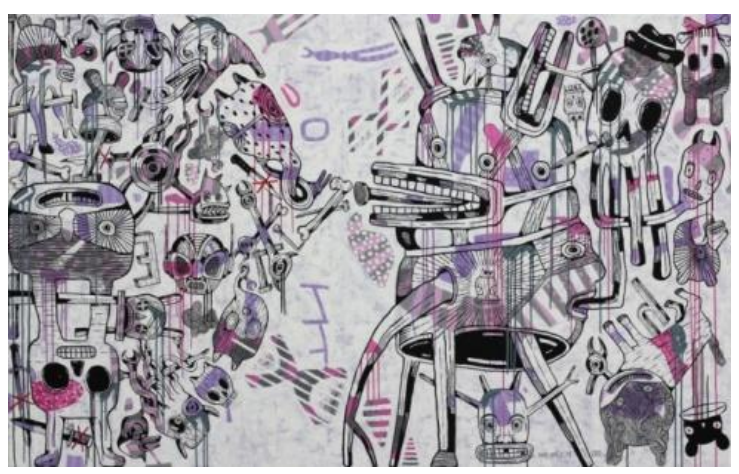

Gambar 18. Eddie Hara, Lost in Wasteland, 2010 (Sumber: Buku Ajar Seni Lukis Madya I)

\section{Hasil Perancangan Batik Postmodernisme}

Contoh hasil perancangan batik postmodernisme adalah sebagai berikut.

\section{Merapi Lereng Ceplok}

Merapi Lereng Ceplok adalah hasil perancangan batik posmodernisme yang memadukan motif batik lereng dan ceplok dengan lukisan Putu Sutawijaya yang berjudul Merapi. Setelah desainnya tercipta, pembuatan pola untuk malam (wax) dilakukan. Akhirnya, batik ini dapat diimplementasikan pada pakaian.

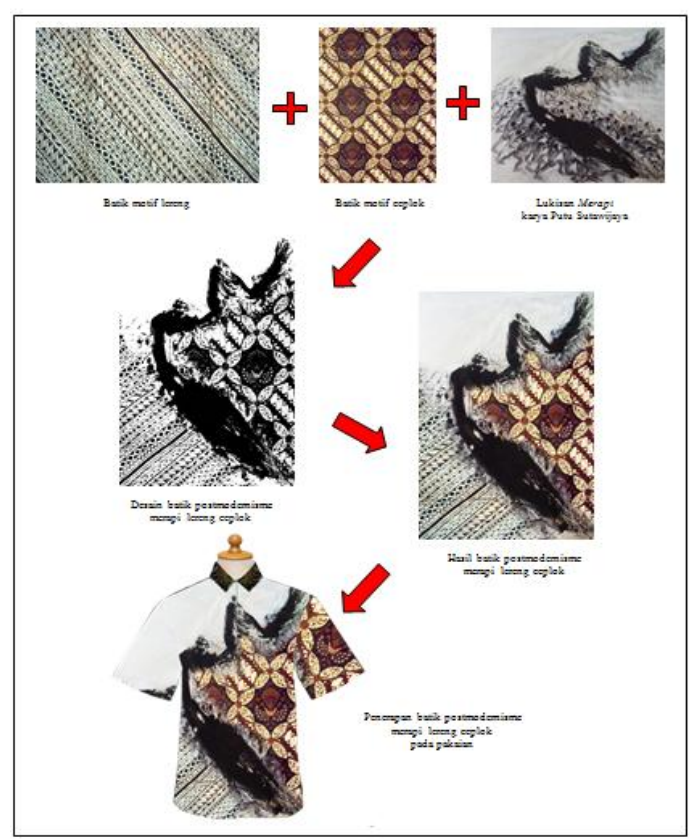

Gambar 19. Perancangan batik postmodernisme Merapi Lereng Ceplok

\section{Matador Sidaluhur}

Matador Sidoluhur adalah hasil perancangan batik posmodernisme yang 
memadukan motif batik sidaluhur dengan lukisan Fadjar Sidik yang berjudul Matador.

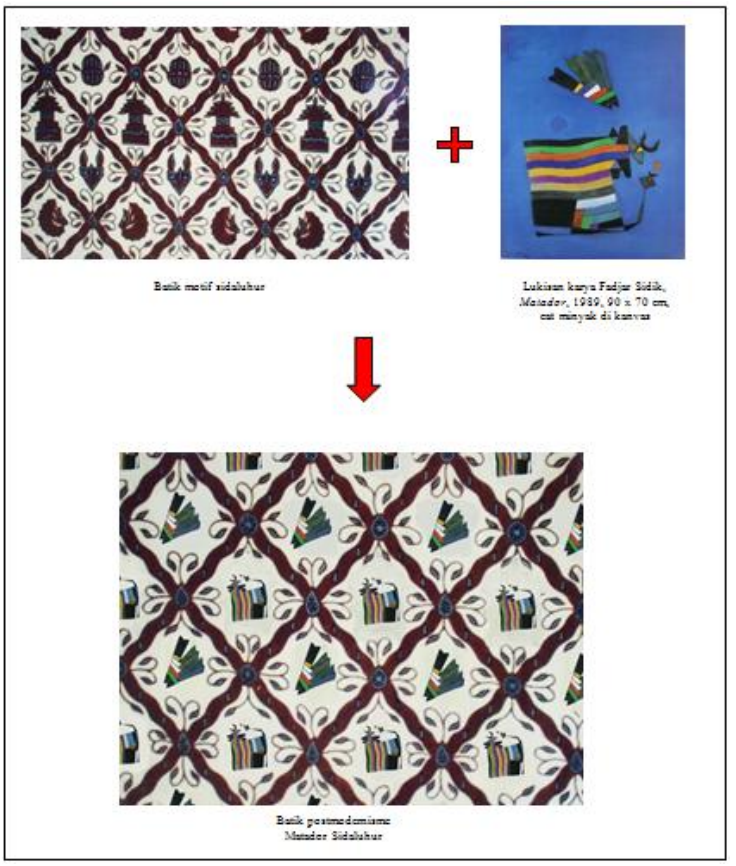

Gambar 20. Perancangan batik postmodernisme Matador Sidaluhur

\section{Parang Kusuma Seling Layang-layang Perlambang \\ Parang Kusuma Seling Layang-layang adalah hasil perancangan batik posmodernisme yang memadukan motif batik parang kusuma seling gandasuli dengan lukisan Nasirun yang berjudul Layang-layang Perlambang.}

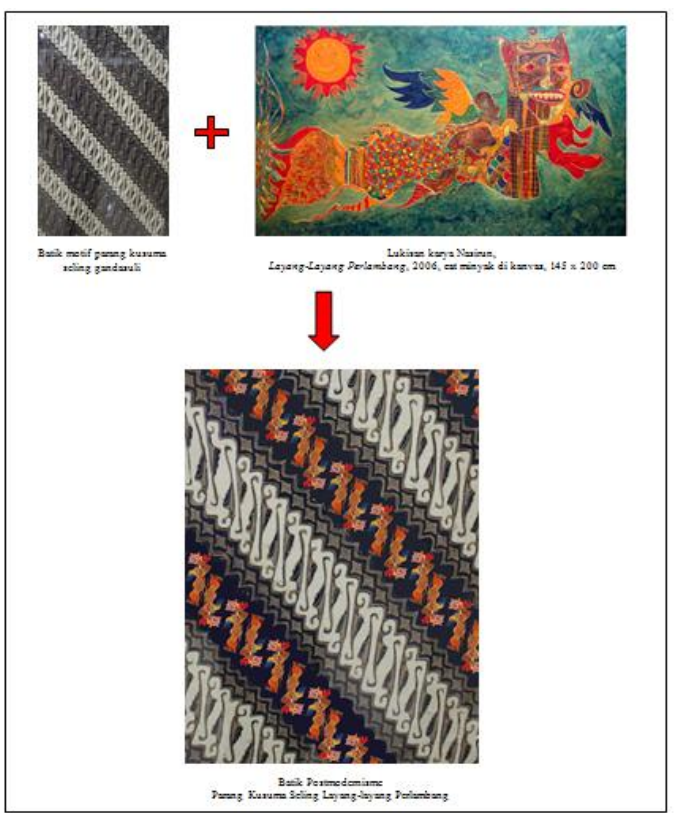

Gambar 21. Perancangan batik postmodernisme Parang Kusuma Seling Layang-layang Perlambang

\section{Matahari Merah di atas Grompol}

Matahari Merah di atas Grompol

adalah hasil perancangan batik posmodernisme yang memadukan motif batik grompol dengan lukisan Affandi yang berjudul Red Sun and Balinese Boat.

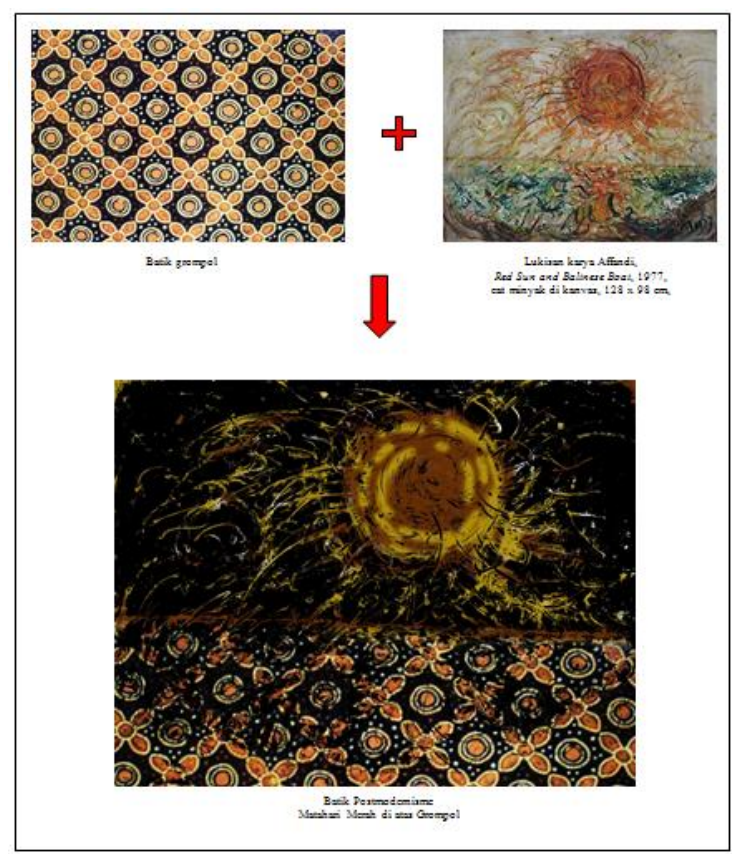

Gambar 22. Perancangan batik postmodernisme

Matahari Merah di atas Grompol

\section{PENUTUP}

Hadirnya seni lukis modern yang pengaruhnya dari barat, tidaklah serta-merta menggusur keberadaan seni tradisional Indonesia, bahkan yang terjadi adalah saling mengispirasi dan mempengaruhi.

Oleh karena itu menghadirkan kemungkinan baru yang mengambil inspirasi dari warisan budaya masa lalu justru harus dilakukan. Mengembangkan teknik dan gaya adalah bagian dari menghidupkan warisan budaya itu sendiri.

Seni batik akan tetap berlangsung dan berkembang jika ide-ide kreatif dan inovatif terus dilakukan oleh masyarakat pendukungnya. 
Daftar Pustaka

Biranul Anas," Indonesia Indah",Yayasan Harapan Kita, 1997.

Buchori Z., Iman, "Aspek Disain dalam Produk Kriya " dalam Seminar Kriya 1990, Institut Seni Indonesia Yogyakarta, 28-29 Mei 1990, di Hotel Ambarukmo Yogyakarta.

Burhan, Agus. 2012. "Affandi dan Perjalanan Estetika Kreatif". Makalah seminar disampaikan di Museum Affandi, Yogyakarta, 9 Juli. . 2006. "Seni Rupa Kontemporer Indonesia: Mempertimbangkan Tradisi", dalam M. Agus Burhan, ed., Jaringan Makna Tradisi hingga Kontemporer Kenangan Purna Bakti untuk Prof. Soedarso Sp., M.A. Yogyakarta: BP ISI Yogyakarta.

Haryono, Timbul. 2008. Seni Pertunjukan dan Seni Rupa dalam Perspektif Arkeologi Seni. Surakarta: ISI Press Solo.

Irianto, Asmujo Jono. 2000. “Konteks Tradisi dan Sosio-Politik dalam Seni Rupa Kontemporer Yogyakarta Era '90-an", dalam Jim Supangkat, ed., Outlet: Yogya dalam Peta Seni Rupa Kontemporer Indonesia. Yogyakarta: Yayasan Seni Cemeti.

Junaedi, Deni. 2011. "Entang Wiharso Lepas dari Zona Nyaman", dalam Majalah Seni Rupa Visual Arts. Jakarta: Vol. 8, Juli-Agustus.

Kemper, A.J. Bernet. 1959. Ancient Indonesia Art. Amsterdam: C.P.J. Van Der Peet.

Kusnadi. "Seni Rupa Modern", dalam Mochtar Kusuma-Atmadja, et al.,ed. Perjalanan Seni Rupa Indonesia dari Zaman Prasejarah hingga Masa Kini.Panitia Pameran KIAS, 1991.

Lombard, Denys. 2008. Nusa Jawa: Silang Budaya Kajian Sejarah Terpadu Bagian II: Jaringan Asia. Jakarta: PT.
Gramedia Pustaka Utama, cetakan ke4.

Marianto, M. Dwi. 2000. "Gelagat Yogyakarta Menjelang Millenium Ketiga", dalam Jim Supangkat, ed., Outlet: Yogya dalam Peta Seni Rupa Kontemporer Indonesia. Yogyakarta: Yayasan Seni Cemeti.

Penghargaan Doctor Honoris Causa Bidang Seni Lukis Modern oleh Institut Seni Indonesia

Yogyakarta.2012.Yogyakarta: Institut Seni Indonesia Yogyakarta.

Piliang, Yasraf Amir. 1995. "Wawasan Semiotik dan Bahasa Estetik PostModernisme"dalam Jurnal Seni Rupa.Bandung: FSRD-ITB, Volume I. 2003. Hipersemiotika: Tafsir Culture Studies Atas Matinya Makna. Bandung: Jalasutra.

Prasetyo, Anindito. 2010. Batik Karya Agung Warisan Budaya Dunia. Yogyakarta: Pura Pustaka.

Ritzer, George. 2004. Teori Sosial Postmodern. Yogyakarta: Kreasi Wacana, cetakan ke-2.

Soetriyono, Eddi. 2007. "Setelah Peluang Dibuka Lelang Dunia", dalam Majalah Seni Rupa Visual Art. Jakarta: Edisi 19, Juni - Juli.

Susanto, Mikke dan M. Dwi Marianto, 2006. "Icon Retrospective", katalog pameran seni rupa. Yogyakarta: Jogja Gallery.

Susanto, Mikke. 2009. “Perupa, Galeri, Kurator Indonesia: Menjadi Internasional", dalam Majalah Seni Rupa Visual Art. Jakarta: Vol. 5, No. 28, Desember Januari.

T. Agus Dermawan. 2010. Gema Waktu Lukisan-Lukisan Abas. Bali: ARMA

Tanama, Albertus Charles Andre. 2011. "Parodi dalam Karya Deni Junaedi", dalam Jurnal Seni Rupa dan Desain Ars. No. XIII, Mei-Agustus. 
Willie, Valentine. 2008. "Stefan Buana Solo di GalNas", katalog pameran. Jakarta: Galeri Nasional Indonesia.

Wisetrotomo, Suwarno. 2006. "On Edi Sunaryo", katalog Pameran Tunggal. Jakarta: Edwin's Gallery.

Yayasan Seni Rupa Indonesia. 1994. "The International Fine Art Exhibition 1994", katalog pameran. Jakarta: Yayasan Seni Rupa Indonesia dan Bradbury International.

Yayasan Seni Rupa Indonesia dan Philip Morris. 1999. "Indonesian Art Awards VI 1999", katalog pameran. Jakarta: Yayasan Seni Rupa Indonesia dan Philip Morris.

Yustiono. 1995. "Seni Rupa Kontemporer Indonesia dan Gelombang PostModernisme", dalam Jurnal Seni Rupa.Bandung: FSRD-ITB, Volume I. 